\title{
Endothelin and aneurysmal subarachnoid haemorrhage: a study of subarachnoid cisternal cerebrospinal fluid
}

\author{
Paolo Gaetani, Riccardo Rodriguez y Baena, Guido Grignani, Giovanni Spanu, \\ Lucia Pacchiarini, Pietro Paoletti
}

\begin{abstract}
Endothelin (ET) is considered one of the most potent vasoconstrictor polypeptides; several experimental studies have suggested its possible role in the pathogenesis of arterial vasospasm after subarachnoid haemorrhage (SAH). Previously reported data on plasma and CSF levels of endothelin in patients with a diagnosis of SAH have been controversial. Cisternal endothelin CSF levels and the possibility that they could be related to vasospasm and other clinical patterns of SAH were investigated. CSF samples were obtained from 55 patients admitted after angiographic diagnosis of intracranial aneurysm. Levels of ET-1 and ET-3 were measured through radioimmunoassay technique. Twelve patients who had operations for unruptured aneurysms were considered control cases; 43 patients with SAH were classified according to: Hunt and Hess grading at admission, vasospasm grading, CT classification and timing of surgery. In all 55 patients ET-1 was measured, while positive levels of ET-3 were found only in 17 cases of 48 . No linear correlation was found between cisternal CSF ET-1 levels when considering time of surgery, CT classification, Hunt and Hess grading at admission, and vasospasm grading. The results of ET-3 assay should be considered with great caution because of the low percentage of positive cases. Cisternal CSF levels of ET-1 and ET-3 are not directly related to the occurrence of arterial vasospasm after the aneurysm rupture, or to other major clinical patterns of SAH; however, ET-1 expression occurs either in paraphysiological (unruptured aneurysm) or in pathological conditions (SAH). It is suggested that ET may potentiate, or may be potentiated by, other factors playing a consistent pathophysiological role in the development of vasospasm.
\end{abstract}

$(\mathcal{F}$ Neurol Neurosurg Psychiatry 1994;57:66-72)

Endothelin (ET) has been shown to be one of the most potent vasoconstrictor polypeptides. ${ }^{1}$ Human genome encodes for three different subtypes which show a constrictive effect in order of ET-1 > ET-2 > ET-3.
Endothelin shows a significant contractile response in cerebral arteries due to a large influx of $\mathrm{Ca}^{++}$through voltage-dependent $\mathrm{C}^{++}$ channels. ${ }^{2}$ Much experimental work has been carried out especially on aneurysmal subarachnoid haemorrhage (SAH) and the possible involvement of ET in the pathogenesis of arterial vasospasm. ${ }^{3-8}$ Two mechanisms were identified in signal transduction in cerebral arteries. $^{9}$ The former is specific for ET-1, depends on a specific receptor largely distributed in CNS, ${ }^{10}$ and is related to the initial vasoconstrictor effect (calmodulin-dependent mechanism). The latter is common to all three ETs and leads to the characteristic and prolonged vasoconstriction through the activation of a $G$ protein and the protein kinase C. ${ }^{11}$ Moreover, ET participates in the enhancement of cellular proliferation in tissues other than vascular endothelium, acting as a local autacoid and activating specific proto-oncogenes. ${ }^{12}$ The endothelial damage due to subarachnoidal blood deposition enhances platelet adhesion and thrombus formation $^{13} 14$ and blood clots and plateletdegradation compounds (thrombin, B-TGF) may induce the synthesis of mRNA encoding for ET and the consequent release of the vasoconstrictive peptide.

However, data available from previous studies on ET levels in the CSF and plasma of patients with SAH are controversial regarding the possible relationship with arterial vasospasm occurrence (table 1). Some authors found a direct correlation between a significant peak in plasma ${ }^{15}$ and $\mathrm{CSF}^{1617} \mathrm{ET}$ 1 levels and the occurrence of symptomatic vasospasm; in other series ${ }^{18}$ no correlation was found between CSF ET levels and vasospasm, although a higher plasma ET-1 level at 8-14 days after SAH was found and related to a possible "stress response" in patients showing clinical signs of vasospasm. ${ }^{18}$ These data do not support the theory that CSF ET levels may represent a predictive factor for clinical outcome, mainly regarding the occurrence of vasospasm.

In this study, we analysed cisternal CSF levels of ET-1 and -3 in a series of 55 patients, to verify any possible correlation with different clinical patterns of the disease: cisternal CSF is strictly in contact with the arterial branches displaying vasospasm and has been considered a more reliable mirror of neurochemical SAH-related patterns, ${ }^{19}$ than ventricular or lumbar CSF. 
Table 1 Summary of data available in reports on measurement of endothelin levels in cerebrospinal fluid of patients after subarachnoid haemorrhage

\begin{tabular}{|c|c|c|c|c|}
\hline Author, year & Metabolite & Source & Number of cases & Comments \\
\hline Suzuki H, $1990^{16}$ & ET-1 & $\begin{array}{l}\text { Cisternal } \\
\text { drainage }\end{array}$ & 26 & Significant increase of ET-1 at day 4-6 after SAH. \\
\hline Fujimori A, $1991^{18}$ & ET-1 & $\begin{array}{l}\text { CSF } \\
\text { Plasma }\end{array}$ & $\begin{array}{l}25 \\
20\end{array}$ & $\begin{array}{l}\text { No correlation with vasospasm onset. } \\
\text { Correlated with vasospasm only in the 2nd week } \\
\text { after SAH (possible "stress response"). }\end{array}$ \\
\hline & $\begin{array}{l}\text { ET-1 } \\
\text { ET-3 }\end{array}$ & $\begin{array}{l}\text { Ventricular } \\
\text { CSF }\end{array}$ & $\begin{array}{l}4 \\
4\end{array}$ & $\begin{array}{l}\text { No correlation with vasospasm. } \\
\text { Significant correlation with vasospasm onset. }\end{array}$ \\
\hline Suzuki R, $1992^{17}$ & ET-1 & Cisternal CSF & 28 & $\begin{array}{l}\text { Increased levels of ET-1 between day 5-7 after } \\
\text { SAH only in patients presenting with vasospasm. }\end{array}$ \\
\hline
\end{tabular}
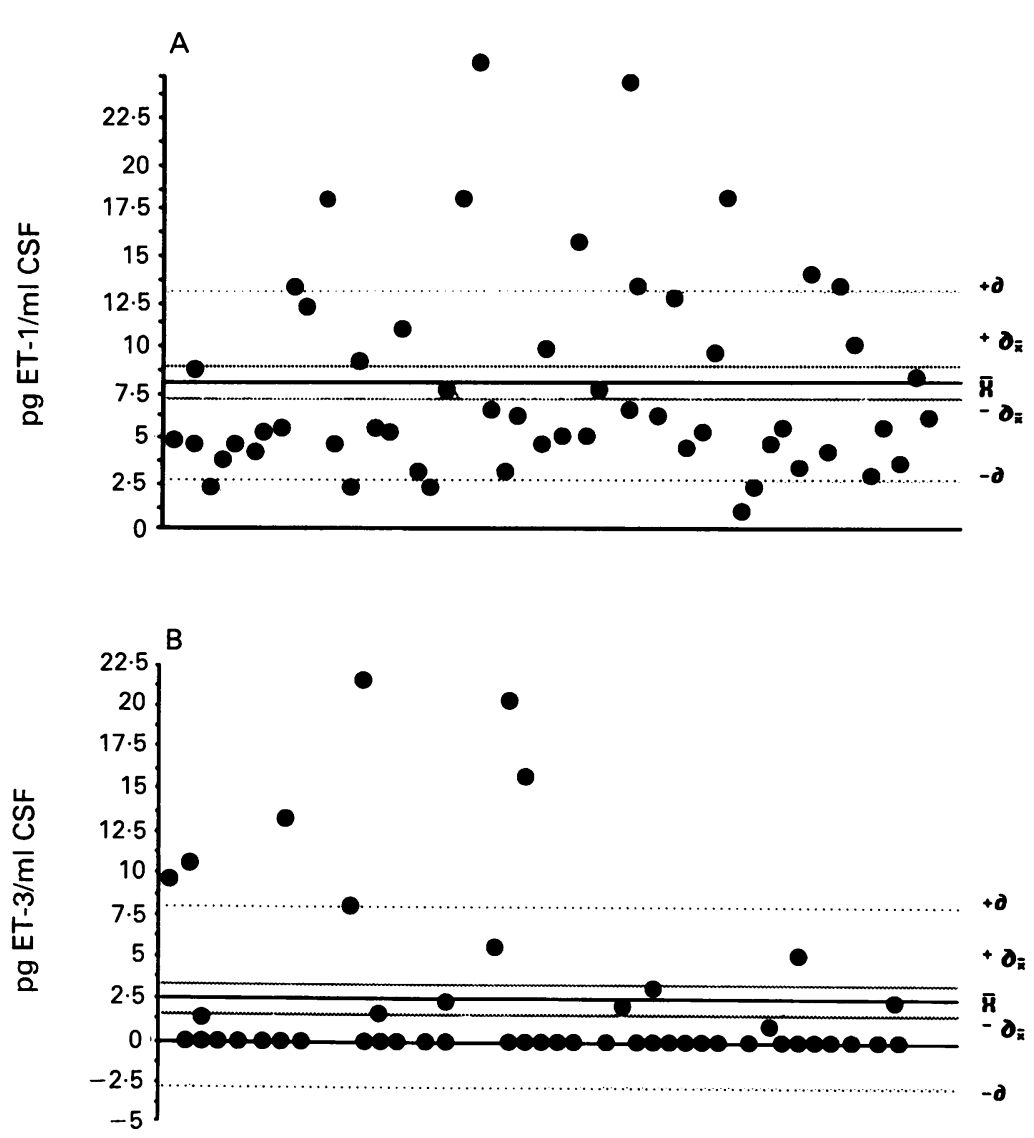

Figure $1 A$ Scattergram of individual cases of cisternal CSF levels of ET-1 in 55 patients operated on for intracranial aneurysm. ET-1 level is expressed in $\mathrm{pg} / \mathrm{ml}$ of CSF. In the scatter plot the mean $(x), S E M$ and $S D$ are represented; $B)$ Scattergram of individual cases of cisternal CSF levels of ET-3 in 47 patients operated on for intracranial aneurysm. ET-1 level is expressed in $\mathrm{pg} / \mathrm{ml}$ of CSF. In the scatter plot the mean (x), SEM and SD are represented. with diagnosis of aneurysmal SAH were included and classified according to different parameters: timing of surgery, CT classification at diagnosis according to Fisher et al,20 and Hunt and Hess grading ${ }^{21}$ at admission.

\section{VASOSPASM ASSESSMENT}

Vasospasm was assessed by angiographic study and transcranial Doppler (TCD) serial measurements. Patients operated on day 1-4 from the last SAH episode had angiography on admission, while patients operated on after the tenth day from the last SAH episode did not have angiography before day 8 post haemorrhage. All patients were studied with serial TCD measurements every second day after $\mathrm{SAH}$, to confirm if there was vasospasm during the maximum expectation time. As in previous reports ${ }^{22} 23$ we considered the mean velocities found in the middle cerebral artery (MCA) and the internal carotid artery (ICA) as there is a significant correlation between vasospasm intensity and flow velocity measured by TCD in these territories. Combining the data of angiographic study (according to Fisher's criteria ${ }^{24}$ ) and TCD, the following groups were considered: vasospasm $(\mathrm{VSP})=$ 0 for patients with unruptured aneurysm; $\mathrm{VSP}=1$ for minimal changes and/or mean flow velocity between 80 and $100 \mathrm{~cm} / \mathrm{s}$ during the first two weeks after SAH; VSP $=2$ for the anterior carotid artery (ACA) and/or MCA diameter at least $1 \mathrm{~mm}$ wide and/or mean flow velocity between 100 and 120 $\mathrm{cm} / \mathrm{s}$; VSP $=3$ for ACA and/or MCA diameter of $0.5 \mathrm{~mm}$ and/or mean flow velocity between 120 and $160 \mathrm{~cm} / \mathrm{s} ; \mathrm{VSP}=4$ for ACA and/or MCA diameter $<0.5 \mathrm{~mm}$ and/or mean flow velocity $>160 \mathrm{~cm} / \mathrm{s}$.

CSF samples were obtained during surgery by cisternal puncture of the subarachnoid cistern the nearest to the aneurysm before aneurysm exclusion. When necessary, patients undergoing early surgery were treated with osmotic agents (mannitol $20 \%$ ), and clonidine. Patients undergoing delayed surgery were treated with tranexamic acid ( $6 \mathrm{~g} /$ day iv) and osmotic agents until surgery.

\section{RADIOIMMUNOASSAY}

All CSF samples were rapidly frozen in vials after centrifugation and stored at $-80^{\circ} \mathrm{C}$ until analysis. The radioimmunoassay (RIA) was performed on the CSF after protein extraction. ${ }^{25}$ ET-1 and ET-3 were measured according to the method of Kraus et al ${ }^{26}$ using kits from Peninsula Laboratories, 

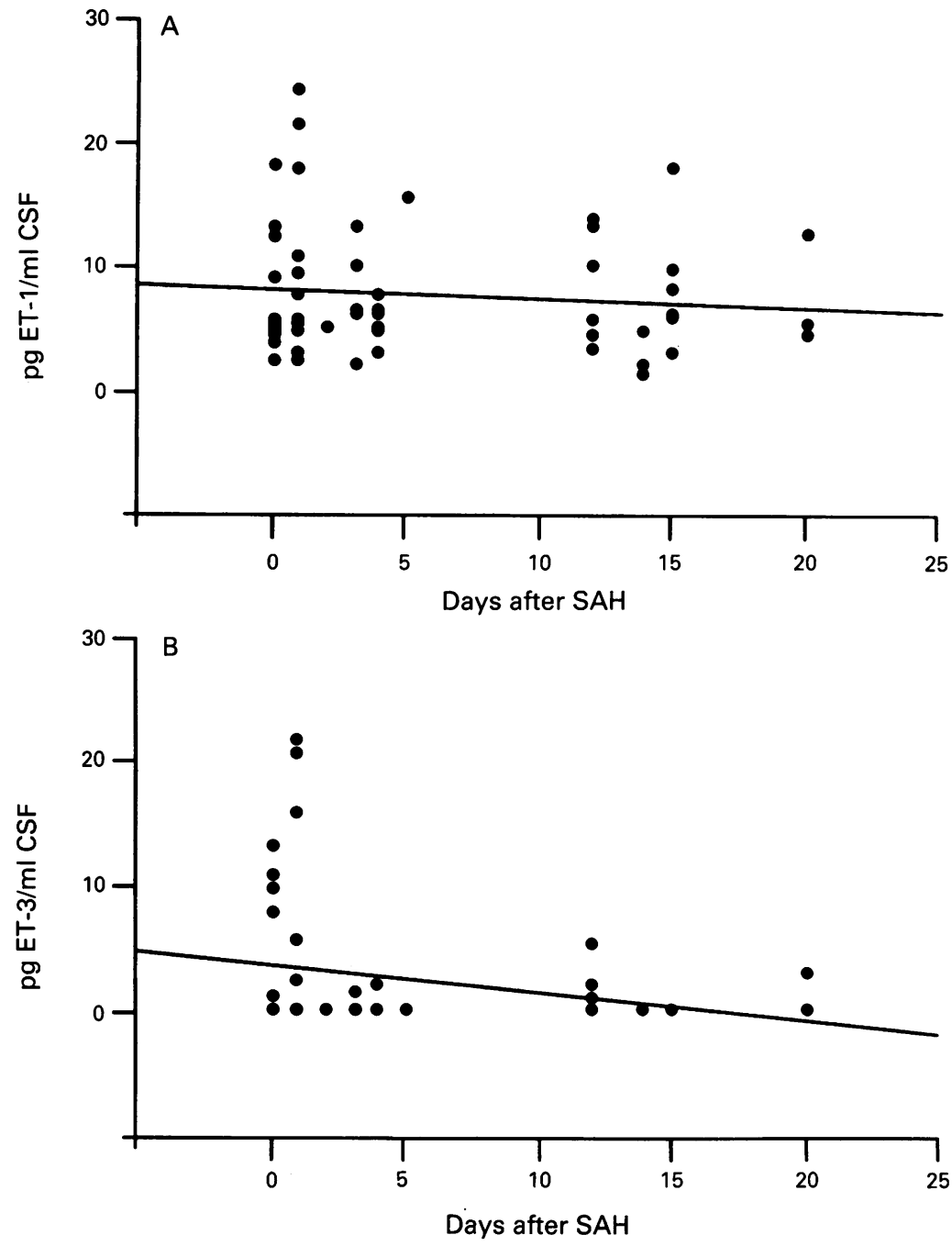

Figure $2 A, B$ Linear regression plot showing the relationship between the time of surgery and cisternal CSF level of ET-1 (fig 2A) and ET-3 (fig 2B). There is no statistical correlation between variables (For $E T-1: R=0.092 ; F$ ratio 0.453; $E T-3: R=0.317$; $F$ ratio 5.042).
Table 3 Cisternal CSF levels of ET-3 ( $p g / m l$ of CSF) in 47 cases of intracranial aneurysm

\begin{tabular}{|c|c|c|c|}
\hline Clinical pattern & Number & Range & Mean (SEM) \\
\hline $\begin{array}{l}\text { CT } 0 \text { (no SAH) } \\
\text { CT } 1 \\
\text { CT } 2 \\
\text { CT } 3 \\
\text { H\&H } 0 \text { (no SAH) } \\
\text { H\&H 1-1 a } \\
\text { H\&H } 2 \\
\text { H\&H } 3 \\
\text { VSP } 0 \text { (no SAH) } \\
\text { VSP } 1 \\
\text { VSP 2 } \\
\text { VSP 3-4 }\end{array}$ & $\begin{array}{r}12 \\
17 \\
10 \\
9 \\
12 \\
17 \\
14 \\
5 \\
12 \\
21 \\
7 \\
8\end{array}$ & $\begin{array}{l}0-13 \cdot 3 \\
0-21.7 \\
0-5 \cdot 22 \\
0-20 \cdot 5 \\
0-13 \cdot 3 \\
0-21 \cdot 7 \\
0-20 \cdot 5 \\
0-5 \cdot 22 \\
0-13 \cdot 3 \\
0-21.7 \\
0-5 \cdot 6 \\
0-5.22\end{array}$ & $\begin{array}{l}3.59(1.5) \\
1.61(1.27) \\
0.77(0.52) \\
5.19(2.56) \\
3.59(1.5) \\
2.16(1.28) \\
2.77(1.77) \\
1.23(1.01) \\
3.59(1.5) \\
3.22(1.5) \\
0.80(0.8) \\
1.07(0.66)\end{array}$ \\
\hline
\end{tabular}

Statistical analysis (ANOVA, Student's $t$ test with Bonferroni correction) revealed no significant differences among subgroups. The extent of subarachnoid clot at CT scan is classi-
fied according to Fisher et al ${ }^{20}$; clinical classification at admission according to the Hunt and Hess grading system ${ }^{21}$, for the classification of arterial vasospasm, see Materials and methods.

\section{STATISTICAL ANALYSIS}

To verify any possible correlation between cisternal CSF levels of ET and different clinical parameters a linear regression analysis was undertaken. Statistical evaluation for intergroup comparison was also performed using ANOVA and Student's $t$ test for unpaired data and the Bonferroni method ${ }^{27}$; statistical significance was $\mathrm{p}<0.05$. Statistical analysis of data regarding ET-3 was recorded considering all the negative cases to be of value 0 , although the percentage of these cases was higher than that of the positive ones. However, a statistical analysis which considered only positive ET-3 values was performed separately.

\section{Results}

In all 55 patients RIA for ET-1 was performed, while only 48 CSF samples were assayed for ET-3. A positive response for ET-1 was observed in all 55 cases; the positive response for ET-3 was significantly lower (17 of 48 cases). Figures $1 \mathrm{a}$ and $\mathrm{b}$ show the scatter plots of the results of ET-1 and ET-3 assays for individual cases.

Four patients showed clinical evidence of arterial vasospasm with angiographical demonstration of high-degree arterial narrowing: for statistical reasons we grouped these cases with six patients classified with grade 3 VSP according to the grading of Fisher et al ${ }^{24}$ and TCD mean velocity $>120 \mathrm{~cm} / \mathrm{s}$, while mild and transient neurological deficits were recorded in this subgroup.

Twelve patients were operated on for unruptured aneurysms and were classified as CT 0 , Hunt and Hess 0 and vasospasm 0. Mean (SEM) ET-1 cisternal CSF level was $7 \cdot 39$ (1.39) (range 2.4-18.3); ET-3 was detected in 5 of 12 cases with a mean (SEM) level of $3.59(1.5) \mathrm{pg} / \mathrm{ml}$ of CSF (range $0-13 \cdot 3)$. Twenty four patients were operated on between day 1 and 4 from the last SAH episode: mean (SEM) cisternal CSF level of ET-1 was $8.56(1.22) \mathrm{pg} / \mathrm{ml}$ and mean ET-3 level (17 cases: 8 positive results) was $4 \cdot 12$ 

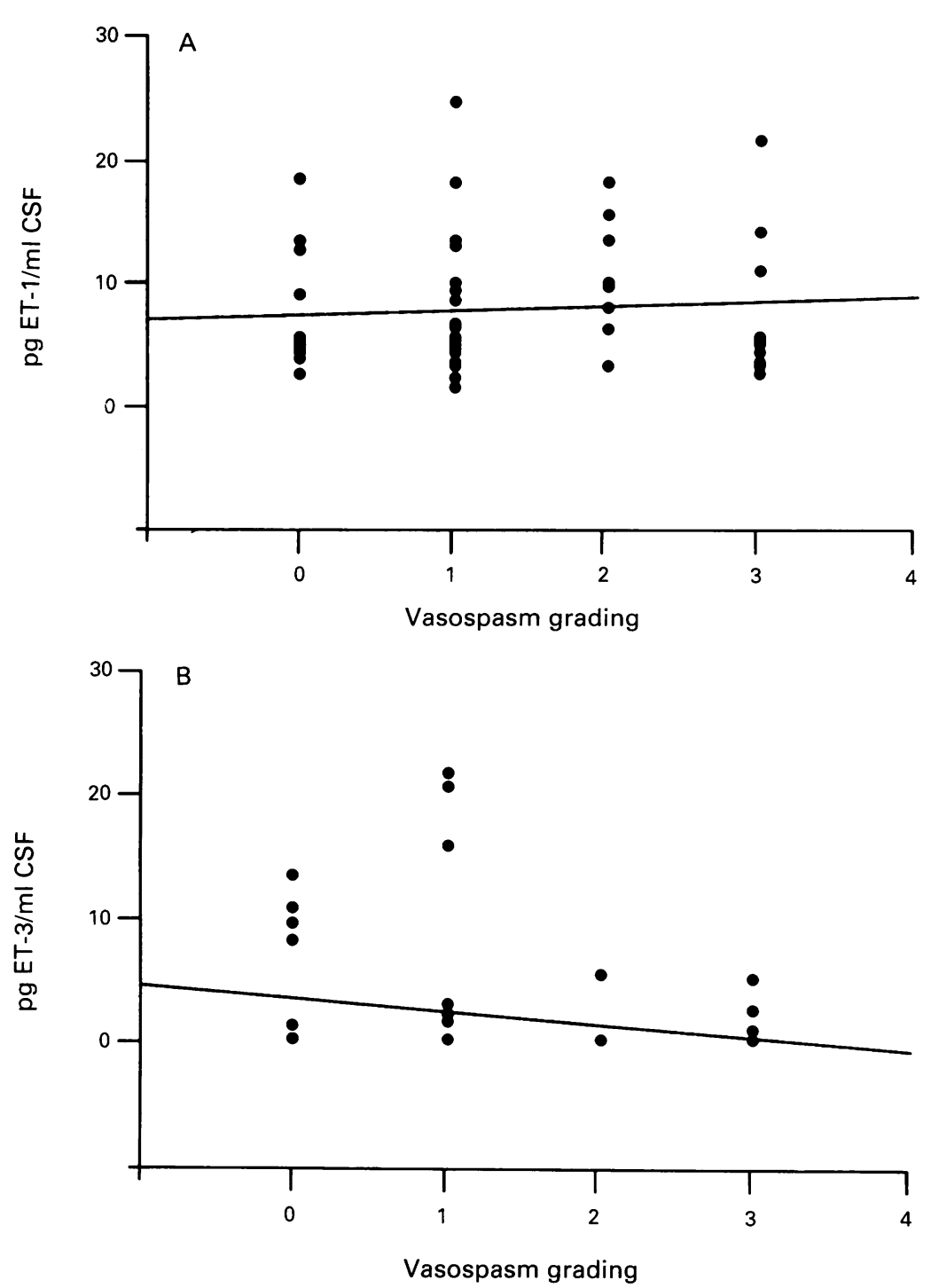

Figure $3 A, B$ Linear regression plot showing the relationship between the vasospasm classification (see Materials and methods) and cisternal CSF level of ET-1 (fig 3A) and ET-3 (fig 3B). There is no statistical correlation between variables (For ET-1: $R=0.072 ; F$ ratio $0.273 ; E T-3 R=0.184 ; F$ ratio $1 \cdot 583)$.

$(1.82) \mathrm{pg} / \mathrm{ml}$. In 19 patients treated in the delayed surgery group, mean (SEM) ET-1 CSF level was $7 \cdot 16(1 \cdot 06) \mathrm{pg} / \mathrm{ml}$ and mean (SEM) ET-3 level was $0.62(0.32) \mathrm{pg} / \mathrm{ml}$ due to the lower number of positive responses (four out of 19 cases). Statistical analysis and in particular linear regression showed no significant correlations between both ET-1 and ET-3 CSF levels and the time of surgery (fig $2 a$ and $b$ ).

Tables 2 and 3 report mean (SEM) of ET1 and ET-3 in different subgroups of patients classified according to the Hunt and Hess grading on admission, CT scan and vasospasm classification. Linear regression showed that there was no significant correlation between ET-1 and ET-3 CSF levels and the clinical patterns considered (fig 3-5).

ANOVA analysis followed by Student's $t$ test and Bonferroni correction showed no statistical differences among subgroups: however, ET-3 levels seem to be slightly higher in cisternal CSF of patients with higher degree of cisternal clot deposition
(CT 3) when compared with CT 1 and CT 2 subgroups; thereafter, the high standard deviation of the data and the relative high level of ET-3 in control cases did not enable us to consider this result definitive. No significant differences were found in ET-3 levels in different subgroups, when only the positive cases were considered.

\section{Discussion}

A considerable amount of experimental work has been published which suggests a possible role for ET-1 in the pathogenesis of arterial vasospasm following aneurysmal SAH. A summary of these data is largely available in recent reviews. ${ }^{12} 26$ ET-1 has a potent constrictor effect on major arteries in vivo in most of the systemic vascular beds, and causes a long-lasting pressor response when injected iv in rats. ET-3 has been shown to have similar effects. ${ }^{26}{ }^{28}$ As for cerebral vasculature, ET-1, only when injected intracisternally, induced a long-lasting vasoconstrictor effect on the basilar artery of cats, ${ }^{29}$ in adult mongrel $\operatorname{dogs}^{4}$ and also induced a significant reduction of regional $\mathrm{CBF}$ in cats ${ }^{30}$ and in rats. ${ }^{31}$ In rats local CBF was also significantly reduced through topical application of ET$1 .{ }^{32}$ When administered into the vertebral artery, ET-1 did not cause any vasoconstrictive effect and was not distributed inside the CNS, except in areas unprotected by the blood-brain barrier. ${ }^{33}{ }^{34}$ Moreover, histological changes shown in the arterial wall after a continuous injection of ET-1 did not significantly differ from degenerative changes observed in spastic basilar arteries of dogs after a double intracisternal injection of arterial blood. ${ }^{5}$

Previously reported values of ET-1 and ET-3 CSF levels after aneurysmal SAH in humans vary widely because of the different methods used in CSF sampling. ${ }^{141626}$ For example, Fujimori et $a l^{18}$ did not find any correlation between serial ET levels obtained in CSF collected through a catheter placed in basal cisterns or in the lateral ventricle, while Kraus et al ${ }^{26}$ reported higher ET-3 levels in CSF collected by ventriculostomy in a small series (four patients with symptomatic vasospasm).

The results of our study suggest that the measurements of cisternal CSF ET-3 levels should be considered with extreme caution. No linear correlation was found between cisternal CSF ET-3 levels, vasospasm grading and the Hunt and Hess clinical classification at admission. Afterwards, the low percentage of positive cases $(<20 \%)$ and the wide data range suggest that, after SAH, ET-3 is rarely seen and might be considered an epiphenomenon of brain damage following the haemorrhage, as in the high levels for head injuries reported by Kraus et al. ${ }^{26}$ Thereafter, CSF ET-3 levels are, in our series, quite low when compared with values reported by others: this might be related to the different technique used in deproteinisation and to the different source of CSF samples.

The analysis of data for ET-1, which is a 


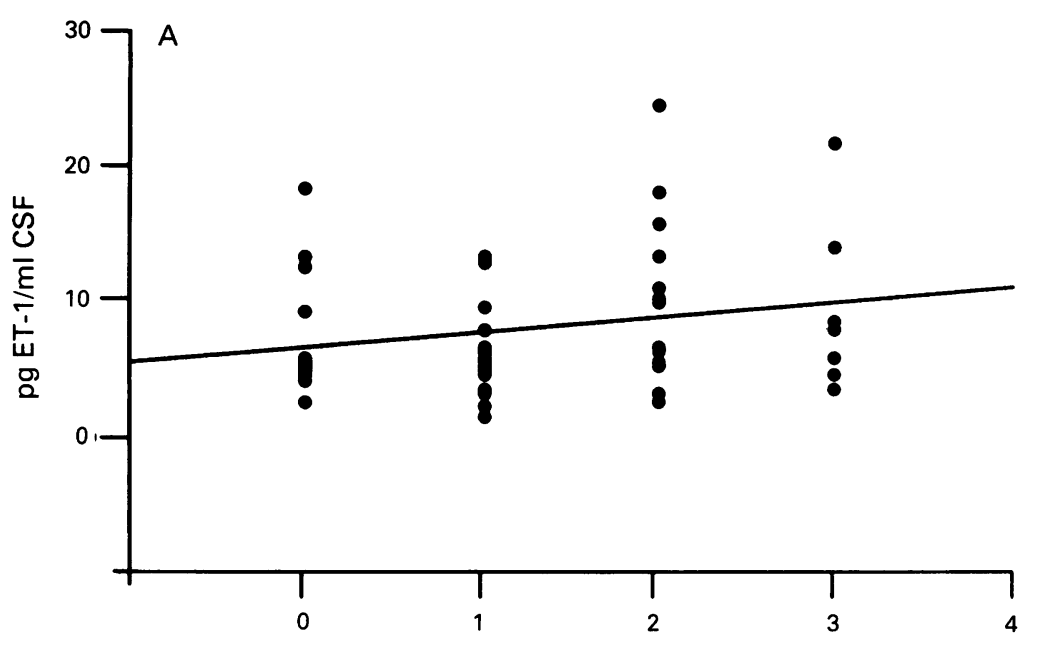

Hunt and Hess grading

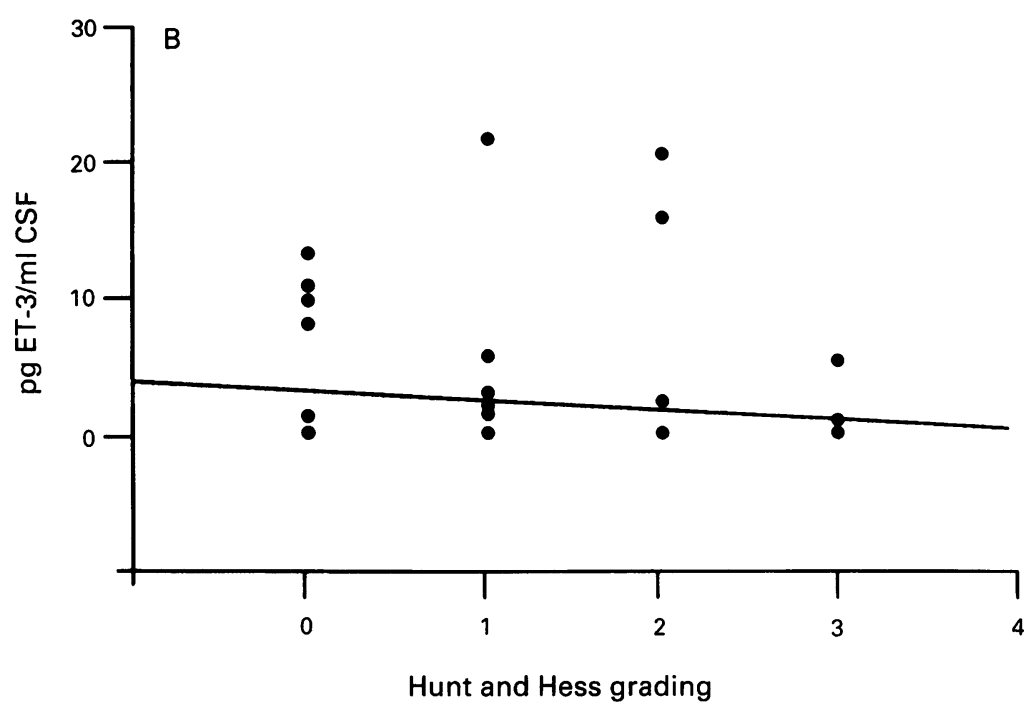

Figure 4A, $B$ Linear regression plot showing the relationship between the Hunt and Hess grade at admission and cisternal CSF level of ET-1 (fig 4A) and ET-3 (fig 4B). There is no statistical correlation between variables (For $E T-1: R=0.221 ; F$ ratio $2 \cdot 729 ; E T-3$ $R=0.099 ; F$ ratio 0.508).
TCD and angiographical classification of arterial spasm which seems to be a more reliable method than the clinical judgment used in other studies. ${ }^{17}$ Conversely, when considering the clinical classification of patients on admission (Hunt and Hess grading system), we observed a slight increase of ET-1 cisternal CSF levels in patients in grades 2 and 3 compared with control cases and to patients with minimal signs (grades 0 and 1 ). However, no direct correlation was found between ET-1 cisternal CSF level and clinical subgroups (fig $3 \mathrm{a}$ ).

Thus the general conclusion from our results is that cisternal CSF levels of ET-1 and -3 are unrelated to vasospasm and to other specific clinical characteristics of aneurysmal SAH; however, some aspects may need emphasis when discussing this lack of correlation.

First, a 'normal range' of CSF ET was not available until now because of the different methods used in deproteinisation and of the different characteristics of CSF samples considered. ${ }^{1835}$ ET does not penetrate through the endothelium and may act only from the adventitial site, as reported in other studies. ${ }^{12} 29$ The CSF sampling from the subarachnoidal cisterns through a direct puncture before the aneurysm exposure and clipping procedure, enabled us to detect a level of ET-1 and ET-3 which was marginally affected by the 'stress response' due to surgical procedures ${ }^{36} 37$ and to avoid questionable interpretations of data obtained through longlasting placement of a cisternal catheter in the subarachnoidal space. ${ }^{37}$

The second instance concerns the biological characteristics of ET which is considered as a local autacoid whose synthesis is regulated at a level of mRNA transcription and may be transiently induced by the accumulation of thrombin, B-TGF, shear stress and other factors after aneurysmal rupture. ${ }^{12}$ Thus measurements of cisternal CSF levels may not reflect events related to a local factor, such as the proliferative angiopathy characteristic of post-haemorrhagic vasospasm.

Third, ET has been demonstrated to activate the phospholipase A2 enzymatic pathway via a $G$ protein and the consequent release of metabolites. In some series this has been correlated with symptomatic vasospasm, such as, leukotrienes ${ }^{19}$ and lipid hydroperoxides. ${ }^{38}$ Thus ET might, at least partly, indirectly participate in mechanisms involved in the pathogenesis of arterial vasospasm.

Finally, we have to take into account that patients with unruptured aneurysm are, as previously discussed, the best control material and that cisternal CSF sampling seems to be a more reliable mirror of local metabolic change than lumbar or ventricular CSF. ${ }^{19}$ Our results suggest that the haemorrhagic event, in view of the different clinical patterns (and mainly vasospasm), does not influence ET-1 and ET-3 synthesis and their release in cisternal CSF. We cannot, however, exclude the possibility that the presence of the abnormal wall of the aneurysm per se may exert 

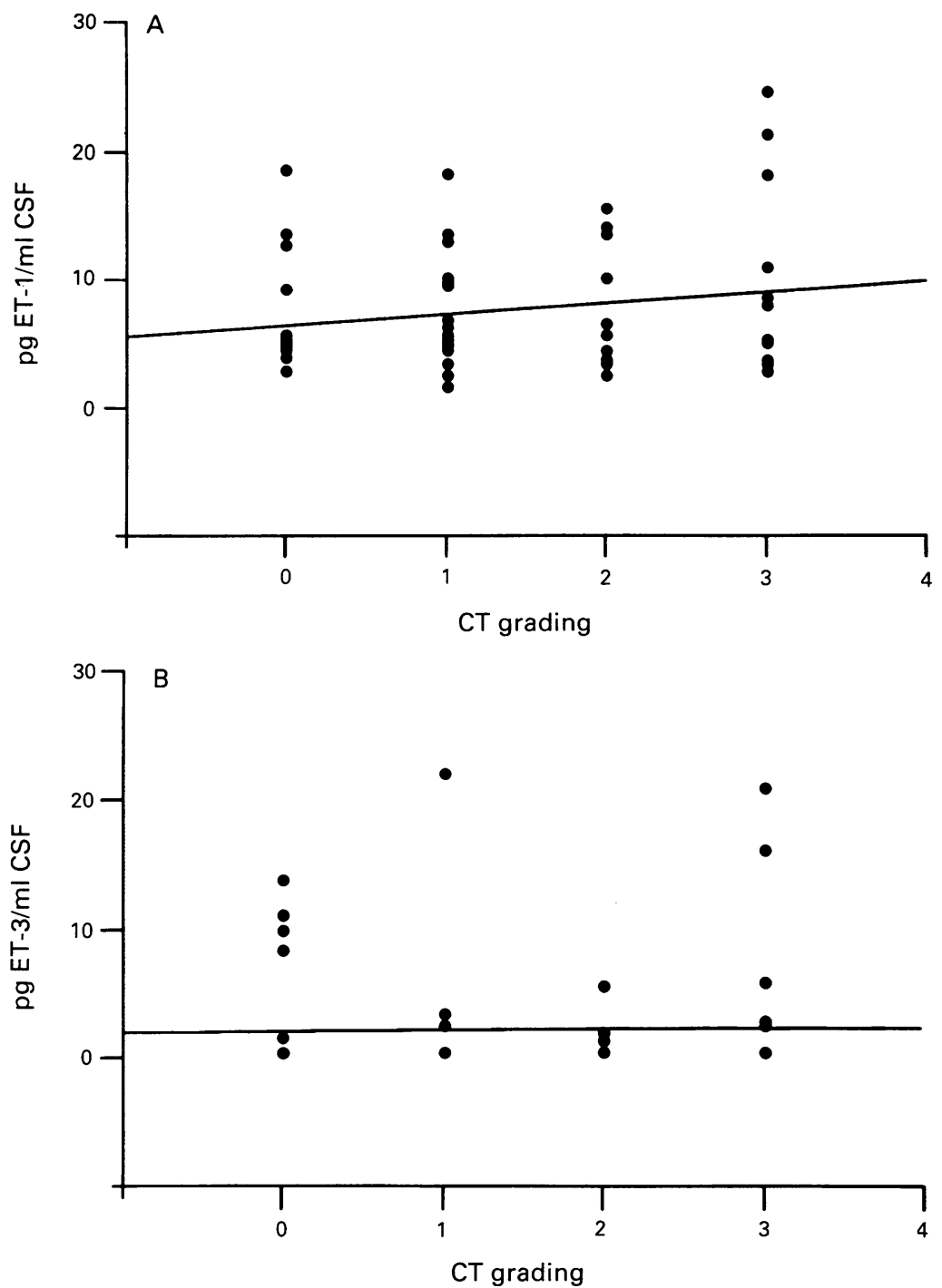

Figure $5 A, B$ Linear regression plot showing the relationship between the $C T$ scan classification of the extent of the subarachnoid clot and cisternal CSF level of ET-1 (fig $5 A$ ) and $E T-3$ (fig 5B). There is no statistical correlation between variables (For $E T-1: R=0.165 ; F$ ratio $1.487 ; E T-3: R=0.058 ; F$ ratio 0.152 ).

some influence on cisternal CSF level of ETs. Given that there is no clear correlation between cisternal CSF ET-1 levels and time of surgery, we speculate that ET-1 may be expressed either in para-physiological or in pathological conditions, such as SAH. In some cases ET may potentiate, or may be potentiated by, other factors, such as haemoglobin derivative factors from the cisternal blood clot, ${ }^{39}$ and leukotrienes or other eicosanoids from the brain compartment, that play a complementary pathophysiological role in the development of arterial vasospasm.

This research was supported by a grant from the Italia Ministry for University and Scientific Research, Rome, 1990.

1 Yanagisawa $M$, Kurihara $H$, Kimura $S$, et al. A novel potent vasoconstrictor peptide produced by vascula endothelial cells. Nature 1988;332:411-5.

2 Tanoi C, Suzuki Y, Shibuya M, Sugita K, Masuzawa K, Asano M. Mechanism of the enhanced vasoconstrictor responses to endothelin-1 in canine cerebral arteries. $f$ Cereb Blood Flow Metab 1991;11:371-9.

3 Asano T, Ikegaki I, Suzuki Y, Satoh S-i, Shibuya M. Endothelin and the production of cerebral vasospasm in dogs. Biochem Biophys Res Commun 1989;159:1345-51.
4 Ide $K$, Yamakawa $K$, Nakagomi $T$, et al. The role of endothelin in the pathogenesis of vasospasm following

5 Kobayashi H, Hayashi M, Kobayashi S, et al. Cerebral vasospasm and vasoconstriction caused by endothelin. Neurosurgery 1991;28:673-9.

6 Nakagomi T, Yamakawa K, Ide K, Sasaki T, Saito I, Takakura K. Role of endothelin-1 in experimental cerebral vasospasm. In: Sano K, Takakura K, Kassell NF, Saski T, eds. Cerebral vasospasm. Tokyo: University Tokyo Press, 1990:242-5.

7 Papadopoulos SM, Gilbert LL, Webb RC, D'Amato CJ. Characterization of contractile responses to endothelin in human cerebral arteries: implications for cerebral vasospasm. Neurosurgery 1990;26:810-5.

8 Suzuki R, Masaoka H, Isotani E, Hirakawa K, Hirata Y. "In vivo" effect of endothelin-1 on the basilar artery of "In vivo" effect of endothelin-1 on the basilar artery of eds. Cerebral vasospasm. Tokyo: University Tokyo Press, eds. Cerebral vasc

9 Jansen I, Fallgren B, Edvinsson L. Mechanism of action of endothelin on isolated feline cerebral arteries: "in vitro" pharmacology and electrophysiology. $\mathcal{f}$ Cereb Blood Flow Metab 1989;9:743-7.

10 Goto K, Kasuya Y, Matsuki N, et al. Endothelin activates the dihydropyridine-sensitive, voltage-dependent $\mathrm{Ca}^{+}$ channel in vascular smooth muscle. Proc Natl Acad Sci USA 1989;86:3915-8.

11 Resink TJ, Scott-Burden T, Buhler FR. Endothelin stimulates phospholipase $C$ in cultured vascular smooth muscle cells. Biochem Biophys Res Commun 1988;157: 1360-8.

12 Shigeno T, Mima T. A new vasoconstrictor peptide, endothelin: profiles as vasoconstrictor and neuropependothelin: profiles as vasoconstrictor and neur
tide. Cerebrovasc Brain Metab Rev 1990;2:227-39.

13 Kobayashi H, Hayashi $M$, Kobayashi S, Kabuto $M$, Handa $Y$, Kawano $H$. Effect of endothelin on the canine basilar artery. Neurosurgery 1990;27:357-61.

4 Nakagomi T, Kassell NF, Sasaki T, et al. Effect of subarachnoid hemorrhage on endothelium-dependent vasodilatation. $\mathcal{f}$ Neurosurg 1987;66:915-23.

15 Masaoka H, Suzuki R, Hirata Y, Emori T, Marumo F, Hirakawa K. Raised plasma endothelin in aneurysmal subarachnoid haemorrhage. Lancet 1989;2:1402.

16 Suzuki H, Sato S, Suzuki Y, Takekoshi K, Ishihara N, Shimoda S. Increased endothelin concentration in CSF in patients with subarachnoid hemorrhage. Acta Neurol in patients with subar

17 Suzuki $R$, Masaoka $H$, Hirata $Y$, Marumo $F$, Isotani $E$, Hirakawa $K$. The role of endothelin-1 in the origin of cerebral vasospasm in patients with aneurysmal subcerebral vasospasm in patients with aneurysmal sub-

18 Fujimori A, Yanagisawa M, Saito A, et al. Endothelin in plasma and cerebrospinal fluid of patients with subarachnoid hemorrhage. Lancet 1991;336:633.

19 Paoletti P, Gaetani P, Grignani G, et al. CSF leukotriene C4 following subarachnoid hemorrhage. $f$ Neurosurg 1988;69:488-93.

20 Fisher CM, Kistler JP, Davis JM. Relation of cerebral vasospasm to subarachnoid hemorrhage visualized by computerized tomographic scanning. Neurosurgery 1980; 6:1-9.

21 Hunt WE, Hess RM. Surgical risk as related to time of intervention in the repair of intracranial aneurysms. f Neurosurg 1968;28:14-9.

22 Aaslid $R$, Huber $P$, Nornes $H$. Evaluation of cerebrovascular spasm with transcranial Doppler ultrasound. cular spasm with transc

23 Harders AG, Gilsbach JM. Time course of blood velocity changes related to vasospasm in the circle of Willis measured by transcranial Doppler ultrasound. $f$ Neurosurg 1987;66:718-28.

24 Fisher CM, Roberson GH, Ojemann RG. Cerebral vasospasm with ruptured saccular aneurysm-the clinical manifestations. Neurosurgery 1977;1:245-8.

25 Suzuki N, Matsumoto H, Kitada C, Masaki T, Fujino $M$. A sensitive sandwich-enzyme immunoassay for human endothelin. F Immunol Meth 1989;118:245-50.

26 Kraus GE, Bucholz RD, Yoon K-W, Knuepfer MM, Smith KR. Cerebrospinal fluid endothelin-1 and endothelin-3 levels in normal and neurosurgical patients: a clinical study and literature review. Surg patients: a clinical

27 Wallenstein S, Zucker CL, Fleiss JL: Some statistical methods useful in circulation research. Circulat Res methods use

28 Spokes RA, Ghatei MA, Bloom SR. Studies with endothelin-3 and endothelin-1 on rat blood pressure and isolated tissues: evidence for multiple endothelin receptor subtypes. $f$ Cardiovasc Pharmacol 1989; 13(suppl 5):S191-2.

29 Mima T, Yanagisawa M, Shigeno $T$, et al. Endothelin acts in feline and canine cerebral arteries from the adventitial side. Stroke 1989;20:1553-6.

30 Morimoto T, Yoshimoto S, Sasaki T, Saito I, Takakura $\mathrm{K}$ : Effect of intracisternal injection of endothelin-1 on regional cerebral blood flow in cats. In: Sano $K$, Takakura K, Kassell NF, Saski T, eds. Cerebral vasospasm. Tokyo: University Tokyo Press, 1990: 256-8.

31 Macrae I, Robinson M, McAuley M, Reid J, McCulloch J. Effects of intracisternal endothelin-1 injection on blood flow to the lower brainstem. Eur $\mathcal{F}$ Pharmacol 1991; 203:85-91. 
32 Robinson MJ, Macrae IM, Todd M, Reid JL, McCulloch $J$. Reduction of local cerebral blood flow to pathological J. Reduction of local cerebral blood flow to pathological levels by endothelin-1 applied to the middle

33 Koseki C, Imai M, Hirata Y, Yanasigawa M, Masaki T. Autoradiographic localization of 125I-endothelinbinding sites in rat brain. Neurosci Res 1989;6:581-5.

34 Sasaki T, Kassell NF, Yamashita M, Fujiwara S, Zuccarello M. Barrier disruption in the major cerebral arteries following experimental subarachnoid hemorrhage. $\mathcal{F}$ Neurosurg 1985;63:433-40.

35 Hoffmann Am Keiser HR, Grossmann E, Godstein DS, Gold PW, Kling M. Endothelin concentrations in cerebrospinal fluid in depressive patients. Lancet 1989;2: 1519.
36 Hirata $\mathrm{Y}$, Itoh $\mathrm{K}$, Ando $\mathrm{K}$, Endo $\mathrm{M}$, Marumo F. Plasma endothelin levels during surgery. $N$ Engl $¥ \mathrm{Med}$ 1989;321:1686.

37 Saito T, Yanagisawa M, Miyauchi T, et al. Endothelin in human circulating blood: effects of major surgical stress. fap $f$ Pharmacol 1989;49(suppl):215.

38 Sano K, Asano T, Tanishima T, Sasaki T. Lipid peroxidation as a cause of cerebral vasospasm. Neurol Res 1980;2:253-72.

39 D'Orleans-Juste $P$, Finet $M$, de Nucci $G$, Vane JR. Pharmacology of endothelin-1 in isolated vessels: effects of nicardipine, methylene blue, hemoglobin, and gossypol. F Cardiovasc Pharmacol 1989;13(suppl):S19- 